Review article

\title{
Lipid phosphate phosphatase 3 in vascular pathophysiology
}

\author{
Marco Busnelli a, *, Stefano Manzini a , Cinzia Parolini a , Diana Escalante-Alcalde ${ }^{\text {, }}$ \\ Giulia Chiesa ${ }^{a, * *}$ \\ a Department of Pharmacological and Biomolecular Sciences, Università degli Studi di Milano, Milano, Italy \\ ${ }^{\mathrm{b}}$ Instituto de Fisiología Celular, División de Neurociencias Universidad Nacional Autónoma de México, Cd. Mx., 04510, Mexico
}

\section{A R T I C L E I N F O}

\section{Article history:}

Received 22 December 2017

Received in revised form

2 February 2018

Accepted 20 February 2018

Available online 2 March 2018

\section{Keywords:}

Lipid phosphate phosphatase 3

Lysophosphatidic acid

Sphingosine-1-phosphate

Genome-wide association studies

Coronary artery disease

Embryonic cardiovascular development

Atherosclerosis

\begin{abstract}
A B S T R A C T
LPP3 is an integral membrane protein belonging to a family of enzymes (LPPs) that display broad substrate specificity and catalyse dephosphorylation of several lipid substrates, including lysophosphatidic acid and sphingosine-1-phosphate.

In mammals, the LPP family consists of three enzymes named LPP1, LPP2 and LPP3, which are encoded by three independent genes, PLPP1, PLPP2 and PLPP3, respectively (formerly known as PPAP2A, PPAP2C, $P P A P 2 B)$. These three enzymes, in vitro, do not seem to differ for catalytic activities and substrate preferences. However, in vivo targeted inactivation of the individual genes has indicated that the enzymes do not have overlapping functions and that LPP3, specifically, plays a crucial role in vascular development.

In 2011, two genome-wide association studies have identified PLPP3 as a novel locus associated with coronary artery disease susceptibility. Shortly after these reports, tissue specific inactivation of PLPP3 in mice highlighted a specific role for LPP3 in vascular pathophysiology and, more recently, in atherosclerosis development.

This review is aimed at providing an updated overview on the function of LPP3 in embryonic cardiovascular development and on the experimental and clinical evidences relating this enzyme to vascular cell functions and cardiovascular disease.
\end{abstract}

(c) 2018 Elsevier B.V. All rights reserved.

\section{Introduction}

Total serum cholesterol and LDL-cholesterol have been established as risk factors for atherosclerosis and its clinical manifestations. However, lipidomic analyses have demonstrated that both lipoproteins and atherosclerotic plaques contain hundreds of molecular lipid species that could play a role in plaque development $[1,2]$. The assessment of these bioactive lipids and the genes/ pathways responsible for their metabolism could improve our comprehension of atherosclerosis aetiology and could provide novel biomarkers to refine coronary artery disease (CAD) risk stratification.

Genome-wide association studies (GWAS) have identified heritable single nucleotide polymorphisms (SNP) in the PLPP3 gene associated with CAD susceptibility [3-6]. PLPP3 (until recently

\footnotetext{
* Corresponding author. Department of Pharmacological and Biomolecular Sciences, via Balzaretti, 9, 20133, Milan, Italy.

** Corresponding author.

E-mail addresses: marco.busnelli@unimi.it (M. Busnelli), giulia.chiesa@unimi.it (G. Chiesa).
}

named PPAP2B) encodes for the Lipid Phosphate Phosphatase 3 (LPP3), an enzyme that catalyses the dephosphorylation of a broad number of extracellular and intracellular lipid substrates [7]. In addition, LPP3 has non-catalytic functions that promote endothelial integrity [8].

Several studies have shown that LPP3 plays a fundamental role in vascular pathophysiology. Recently, we have demonstrated that hepatic deficiency of LPP3 worsens atherosclerosis development through modulation of the plasma lipidome, specifically increasing the concentration of low-abundant pro-atherogenic lipid species [9].

This review is aimed at providing an updated overview of the clinical and experimental findings that link LPP3 to vascular development and atherosclerosis.

\section{Structure and functions of LPP3}

LPP3 is an enzyme that belongs to the family of phospholipid phosphate phosphatases (LPPs) and catalyses the dephosphorylation of a broad number of extracellular and intracellular lipid substrates. Mammalian LPPs were first characterized in 1991 as 
phosphatidic acid (PA) phosphatases [10], but it was subsequently demonstrated that they act on a wide variety of lipid phosphates, including lysophosphatidic acid (LPA), sphingosine-1-phosphate (S1P), ceramide-1-phosphate (C1P) [11], diacylglycerol pyrophosphate [12] and N-oleoylethanolamine phosphate [13].

Mammalian LPPs consist of three related proteins named LPP1, LPP2 and LPP3, which form both homo- and hetero-oligomers [14] and are irregularly distributed in plasma membrane, caveolae, endoplasmic reticulum, Golgi and cytoplasmic vesicles [15-18].

\subsection{LPP3 structure}

The crystal structures of LPPs have not yet been solved, thus the predicted topology and mechanism of action have either been predicted by computational modelling or inferred from the crystallographic structure of a related enzyme [19-21].

LPP3 is predicted to possess six transmembrane $\alpha$-helices and an active site comprised of three regions ( $\mathrm{C} 1, \mathrm{C} 2$ and $\mathrm{C} 3$ ) localized on the extracellular side of the plasma membrane or on the luminal surface of intracellular organelles. The catalytic domains C1 and C2 are located between the transmembrane $\alpha$-helices III and IV, whereas C3 is located between the helices V and VI. C1 is responsible for substrate recognition, whereas C2 and C3 mediate the phosphotransferase reaction [19] (Fig. 1).

\subsection{LPP3 functions}

Dephosphorylation of extracellular LPA and S1P - The most relevant function of LPP3, as well as LPP1 and LPP2, is considered to be the dephosphorylation of extracellular LPA and S1P at the cell surface (Fig. 2).

LPA is a glycerophosphate normally present in extracellular fluids and is mostly produced through the hydrolysis of lysophosphatidylcholine (LPC) by secreted autotaxin (ATX) [22]. LPC itself is mainly secreted by hepatocytes [23], but also originates from the action of lecithin:cholesterol acyltransferase on HDL [24]. In addition, LPA is produced by secretory phospholipase $A_{2}$, which hydrolyzes PA in microvesicles shed from cells during inflammation [25] and platelet aggregation [26].

LPA exerts its action through at least six G protein-coupled receptors $\left(\mathrm{LPA}_{1}-\mathrm{LPA}_{6}\right)$ as well as one nuclear receptor, the peroxisome proliferator activated receptor $\gamma$ [27].

LPA has recently gained great importance as a critical oncogenic mediator, being involved in the regulation of cellular activities such

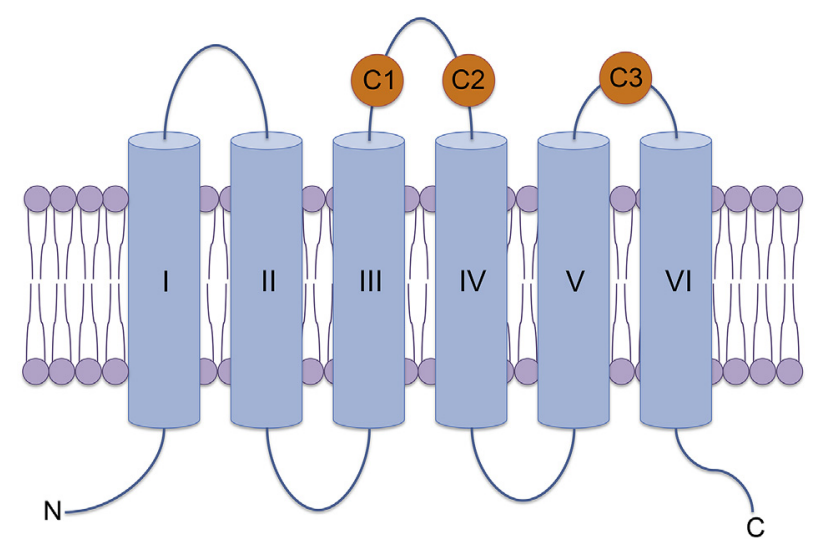

Fig. 1. LPP3 structure.

LPP3, as well as LPP1 and LPP2, is predicted to possess six transmembrane $\alpha$-helices (I$\mathrm{VI})$ and three catalytic domains (C1, C2 and C3) localized on the extracellular side of the plasma membrane or on the luminal surface of intracellular organelles.

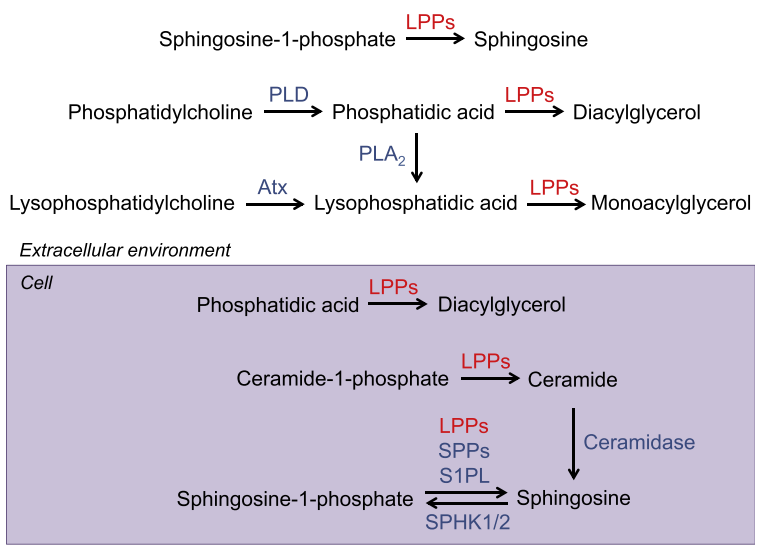

Fig. 2. Metabolism of extracellular and intracellular bioactive lipids by LPP3.

The main function of LPP3 is considered to be the dephosphorylation of extracellular lysophosphatidic acid and sphingosine-1-phosphate at the cell surface. LPP3 can also regulate intracellular signalling by dephosphorylating intracellular phosphatidic acid, ceramide-1-phosphate and sphingosine-1-phosphate. The described extracellular and intracellular functions belong to all LPPs. SPPs, sphingosine-1-phosphate phosphatases; S1PL, sphingosine-1-phosphate lyase; SPHK1/2, sphingosine kinase $1 / 2$; PLD, phospholipase D; PLA 2 , phospholipase $\mathrm{A}_{2}$; ATX, autotaxin.

as cell proliferation, tissue invasion, and metastasis [28-30].

LPA promotes wound repair by stimulating platelet aggregation and cell migration into the wounded area [18]. Moreover, LPA stimulates the conversion of monocytes into macrophages [31], modulates lymphocyte extravasation [32,33] and, in chronically inflamed tissues, promotes lymphocyte invasion and increases cytokine production [34,35].

These actions suggest a possible role of LPA in atherosclerosis. In mice, increased amounts of circulating LPA have been shown to have pro-atherosclerotic effects [36]. In humans, an increased serum concentration of LPA associates with the occurrence of coronary syndromes [37]. LPA accumulates in the atherosclerotic plaque and it can exacerbate plaque progression. In particular, previous studies have highlighted that LPA is abundant within the lipid-rich core region of the plaques, where it may trigger intraarterial thrombus formation following plaque rupture [38].

LPPs, by dephosphorylating LPA, interrupt its receptor-mediated signalling actions. The liver seems to play a major role in LPA catabolism [39], as also supported in a recent study, where liverspecific deletion of Plpp3 in mice, increased plasma LPA concentration [9].

S1P is a sphingolipid analogue of LPA formed intracellularly through phosphorylation of sphingosine by sphingosine kinase 1 and 2 [40]. Inside the cells, sphingosine is derived from ceramide, which is synthesized de novo or from the breakdown of membraneresident glycosphingolipids and sphingomyelin [41].

The main sources of circulating S1P are red blood cells and vascular endothelial cells (EC) [42-44]. The sphingolipid transporter 2 is used by EC for S1P secretion [45]. Platelets also contribute to the release of S1P when activated and during clot formation [40].

Within the plasma, S1P is bound to HDL ( 60\%), albumin ( $30 \%)$, VLDL and LDL [46]. S1P is bound to HDL via apoM, which acts as a chaperone, protects S1P from degradation and facilitates S1P presentation to receptors [40].

Extracellular S1P exerts its effects by interacting with a family of five $\mathrm{G}$ protein-coupled receptors $\left(\mathrm{S}_{1} \mathrm{P}_{1-5}\right)$, and it regulates several physiological processes, including vascular development and function [47-49], hematopoietic cell trafficking [50,51], and nervous system development [52]. 
S1P is thought to be involved in several diseases including cancer [53], diabetes [54], congenital disorders [55], kidney diseases [56], and immunological diseases [57].

Plasma S1P levels have been reported to be lower in subjects with CAD [58], although several studies have indicated that S1P possesses a dual nature in the pathogenesis of atherosclerosis. Specifically, S1P bound to HDL exhibits anti-atherosclerotic effects [59] whereas S1P bound to albumin seems to exert both beneficial and harmful effects during atherosclerosis development. HDLassociated S1P is cytoprotective and prevents the apoptosis of EC [60-62], preserves the stabilisation of EC-cell junctions [63], and induces the phosphorylation of eNOS, thereby promoting the relaxation of vessels $[64,65]$. In addition, S1P reduces the adhesion of leukocytes to the vessel wall by lowering the expression of VCAM1 and ICAM1 on EC [65,66].

Conversely, albumin-bound S1P, besides anti-atherosclerotic effects, can drive the recruitment of lymphocytes to sites of inflammation [67,68] and promote macrophage chemotaxis [69,70].

S1P is degraded by three types of enzymes: S1P phosphatases (SPPs), S1P lyase (S1PL), and LPPs. LPPs are the only enzymes that have the ability to degrade extracellular S1P, being SPPs and S1PL localized in the endoplasmic reticulum [71]. LPP3 plays an important role in shaping S1P gradients in the spleen, thymus and cerebellum as well [72-74].

Intracellular functions - LPPs can regulate intracellular signalling, being localized also on the luminal side of the endoplasmic reticulum and the Golgi network membranes [75,76]. LPPs could potentially modulate inflammation [77], gene transcription [78], cell proliferation and apoptosis [79], by dephosphorylating intracellular C1P and S1P (Fig. 2). Manipulations of LPP expression have been shown to alter the levels of cell-associated LPP substrates and products, including PA and its dephosphorylated product diacylglycerol (DG) [17] that are well known to regulate intracellular signalling pathways $[80,81]$. The lack of LPP3 reduces the levels of de novo synthesized DG and the Golgi-associated DG content, with the consequent impairment of protein trafficking in the early secretory pathway [82]. In addition, LPP2 and LPP3 decrease cell survival by reducing the intracellular levels of PA that, together with S1P, has been shown to protect cells from apoptosis [83].

Noncatalytic functions - Beyond its phosphatase activity, LPP3 binds to integrins at the plasma membrane and promotes endothelial cell-to-cell adhesion. Both human and rodent LPP3 recognize $\alpha_{v} \beta_{3}$ and $\alpha_{5} \beta_{1}$ integrins [84,85], and LPP3 inhibition blocks the EC aggregation mediated by these two integrins [84]. In humans, this interaction relies on an arginine-glycine-aspartate (RGD) recognition motif on LPP3, which is located in the second extracellular loop, between the transmembrane $\alpha$-helices III and IV [86]. Even though in mouse and rat the corresponding sequence is arginine-glycine-glutamate (RGE), murine LPP3 can also interact with $\alpha_{v} \beta_{3}$ and $\alpha_{5} \beta_{1}$ integrins [84].

\section{The PLPP3 gene}

The nomenclature of the LPP gene family has been recently changed to better reflect the relationship between the gene and its product. As such, PLPP3, previously known as PPAP2B, is the official gene symbol for the gene encoding for LPP3. This gene appears to be conserved in the vast majority (more than 90\%) of living vertebrates [87].

In humans, PLPP3 is located on chromosome 1 and it spans 150,827 base pairs. Five transcripts are generated from the gene, but only one results in the formation of a protein product of 311 aminoacids. This transcript is assembled from 6 exons into a mature mRNA of 3292 base pairs.
Because of the extensive use that has been done in model organisms, the mouse orthologue Plpp3, located on chromosome 4, is of particular interest. When compared to the human, the murine gene shows remarkable similarity in both intron/exon structure (same number and comparable length), with an $89 \%$ identity at cDNA level and a $94 \%$ at protein level.

The chromosomal regions around human and mouse genes are highly syntenic. Within 5 megabases at either side of PLPP3/Plpp3, 195 transcripts are annotated in human and 192 in mouse. Of these, 55 protein-coding genes are conserved and show the same spatial distribution. Genes that do not correlate, owing to a different annotation scheme, are mainly non-coding RNA genes and pseudogenes. Among the 55 conserved protein-coding genes, the locus hosts other genes involved in atherosclerosis and lipid metabolism (Fig. 3). Interestingly, within $\sim 1.5 \mathrm{MB}$ in human and $\sim 1.3 \mathrm{MB}$ in mouse lies PCSK9, encoding the Proprotein Convertase Subtilisin/ Kexin Type 9, a protease involved in the regulation of the LDL receptor trafficking [88]. Other nearby genes encode proteins dealing with cholesterol metabolism including SCP2 (Sterol Carrier Protein 2) [89], OSBPL9 (Oxysterol Binding Protein Like 9) [90], DHCR24 (24Dehydrocholesterol Reductase) [91], and LRP8 (LDL Receptor Related Protein 8) [92]; moreover, enzymes that process fatty acids are present, like ACOT11 (Acyl-CoA Thioesterase 11) [93], CPT2 (Carnitine Palmitoyltransferase 2) [94], and ECHDC2 (Enoyl-CoA Hydratase Domain Containing 2) [95]. A little farther, LEPR, the Leptin Receptor gene [96], is also present.

PLPP3 is broadly expressed, showing detectable levels in almost all tissues $[9,75]$. Nervous system, liver, lung, pancreas, eye, thyroid gland, heart are organs where PLPP3 expression is reportedly higher and consistent [97].

As described in previous paragraphs, the three mammalian LPPs display overlapping activities and substrate preferences. Nevertheless, the use of several genetically modified mouse models have demonstrated that the three proteins are not functionally redundant.

Mice harbouring a gene-trap inactivation of Plpp1, encoding murine LPP1, are phenotypically unremarkable [98], even though multiple tissues isolated from these animals display a reduced ability to dephosphorylate exogenously provided LPA. Similarly, the lack of Plpp2, encoding murine LPP2, does not result in phenotypic alterations [99].

In contrast, a constitutive deletion of Plpp3 in mice results in embryonic lethality, largely due to defects in extraembryonic vascular development [100].

\section{Role of LPP3 in embryonic cardiovascular development}

As mentioned previously, in mice, knockout of Plpp3 yields severe developmental abnormalities, including lack of chorioallantois fusion, allantois compaction, and limited formation and remodelling of the yolk sac (YS) vascular plexus and haemorrhage, leading to early lethality around embryonic day (E) 9.5 [100]. Chimaera analysis showed that $\mathrm{Plpp}^{-1-}$ cells are unable to contribute to the umbilical [100] and embryonic vasculature (Fig. 4A) indicating a cell autonomous requirement for LPP3 expression in EC. This was confirmed in two studies analysing the effects of the conditional inactivation of Plpp3 in endothelial and some hematopoietic cells. Lack of LPP3 in EC also resulted in embryonic lethality. Although mutant embryos were recovered between E9.5-E13.5, all showed vascular abnormalities such as pale YS, deficient remodelling of the YS vascular plexus, YS and embryo vascular leakage, irregular intersomitic vasculature, defective sprouting of the tail's blood vessels and poor development of cephalic vascular networks [8,101]. In these embryos, abnormal vascular development was associated with the loss of barrier 


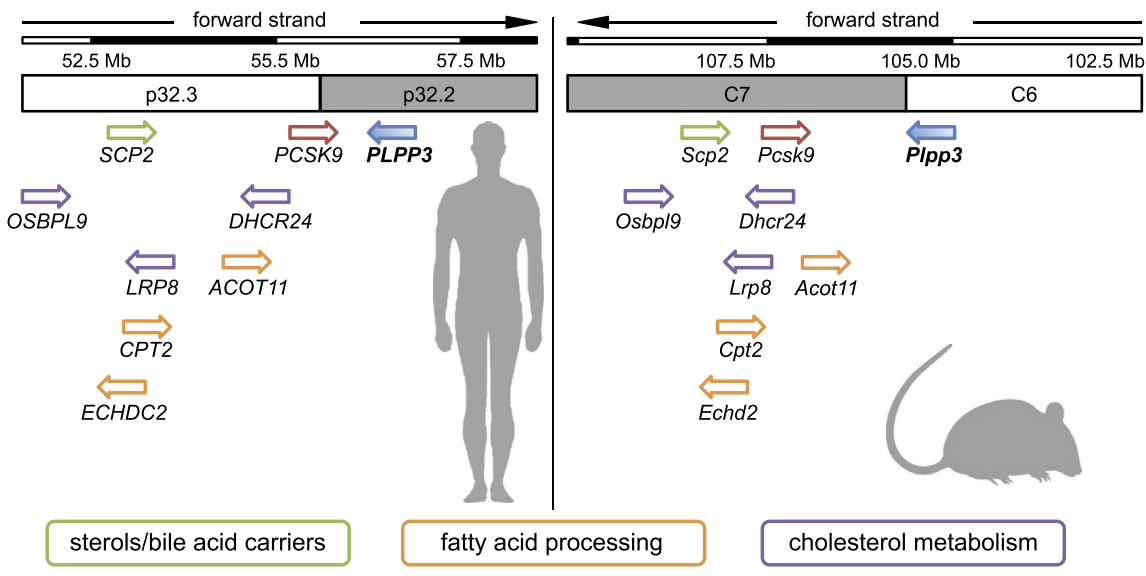

Fig. 3. The PLPP3/Plpp3 locus.

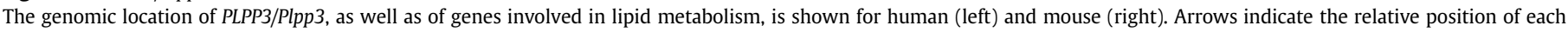
gene, but are not drawn to scale. Mb, megabase (million base pairs).

integrity leading to increased apoptotic cell death of EC. In addition, as a consequence of the loss of $\beta$-catenin-mediated transcriptional activity caused by the lack of LPP3 in EC [102], a strong reduction in the expression of several target genes important for EC proliferation and for the maintenance of the vascular integrity was observed [8].

Whether the vascular abnormalities found in $\mathrm{Plpp}^{-1-}$ embryos or in embryos lacking the protein in EC arise from the loss of catalytic activity and/or its role as a cell-cell adhesion molecule in EC $[84,85]$ remains to be established. However, indications that its catalytic activity plays a predominant role come from models with altered LPA- and S1P-signalling. In zebrafish, the ATX/LPA axis regulates blood vessel development through $\mathrm{LPA}_{1,4,6}$ receptors [103], while no obvious developmental or vascular defects were observed in maternal and/or zygotic mutants for most zebrafish S1P receptors [104] (except for S1pr2, see below). Additionally, knocking out or overexpressing Enpp2/Atx in mice results in similar defects that are strikingly similar to those found in embryos lacking global expression of LPP3 [105,106]. Additionally, it has been described that LPP3 enhances endothelial cell-cell interactions by downregulating $\mathrm{LPA}_{6}$ receptor signalling in human umbilical vein endothelial cells [107]. On the other hand, analysis of mouse embryos lacking both S1P-synthesizing enzymes, sphingosine kinase 1 and 2, revealed widespread hemorrhaging and defects in remodelling of vascular networks mainly in the head region, with embryo lethality occurring around E12.5, demonstrating that S1P-mediated signalling also participates in vascular development [52]. In addition, S1pr1 gene inactivation produces abnormal vascular maturation in the embryo, demonstrating that S1P-mediated signalling also participates in vascular development [108].

Besides the key participation of LPP3 in vascular development, evidence suggests it also plays a role in heart development (Fig. 4B'$\left.\mathrm{D}^{\prime}\right)$. A small proportion of Plpp3 ${ }^{-1-}$ embryos reaching E8.5 displayed cardia bifida [100] suggesting that LPP3 participates in the morphogenetic movements required for the formation of the linear heart tube (Fig. 4B and $\mathrm{B}^{\prime}$ ). Additionally, conditional inactivation of Plpp3 in EC evidenced its key participation for posterior heart development, in particular on the formation of endocardial cushions (primordia of the cardiac valves and septa), trabeculation and compact myocardium growth (Fig. 4C, C', D, D') [8,101]. Although the mechanism leading to these phenotypes in mice remains to be established, it is tempting to speculate that lipid mediated signalling is also involved. In zebrafish, defects in endoderm convergence, regulated by $\mathrm{S} 1 \mathrm{P} / \mathrm{S} 1 \mathrm{PR} 2$ signalling, leads to cardia bifida [55,109-112]. Likewise, analysis of developing hearts from S1 pr $1^{-1-}$ mouse embryos revealed that S1P-mediated signalling through this receptor is required for proper endocardial cushions, trabeculae and compact myocardial wall development [113].

Altogether, these observations suggest that many of the abnormalities found in embryos lacking general or EC expression of LPP3 could result from alterations in the fine regulation of LPA- and S1Psignalling required for proper cardiovascular development.

\section{Association between PLPP3 polymorphisms and human cardiovascular disease}

Atherosclerosis, in the form of CAD, is known to have a high heritability [114]. For many decades the strategies to identify the genetic variants underlying this heritability were unsuccessful [115], but, over the last few years, methodological advances and collaborative efforts have allowed a significant progress. GWAS have identified several common variants associated with the risk of CAD [116]. The number of variants identified by this approach was markedly increased by the formation of large, international consortia that, allowing the analysis of a very high number of study subjects, accumulated a sufficient statistical power for new discoveries. More than 90 genomic loci harbouring genetic variants associated with CAD at genome-wide levels $\left(p<5 \times 10^{-8}\right)$ have been identified so far [6,117-119]. The contribution of each locus to the overall risk is small. However, the study of the gene pathways mediating risk at each locus will potentially contribute to the identification of novel strategies in prevention and therapy.

In 2011, two GWAS identified PLPP3 as a new CAD locus. The most significant variants associated with increased risk of CAD in these studies were two SNPs, rs17114036 and rs17114046, both located in intronic sequences of PLPP3 and correlated with each other $[3,4]$. The association of rs17114036 with CAD susceptibility was further confirmed in wider GWAS, carried on subjects mostly of European ancestry [5,6,119]. Recently, a case-control study in the Chinese Han population associated the PLPP3 rs1759752 polymorphism with an increased risk of CAD in males and a genetic variant at rs12566304 with a decreased risk of CAD in females [120].

The potential relationship between polymorphisms in five different genes, including PLPP3 rs17114036, and subclinical atherosclerosis was also investigated in patients with rheumatoid 

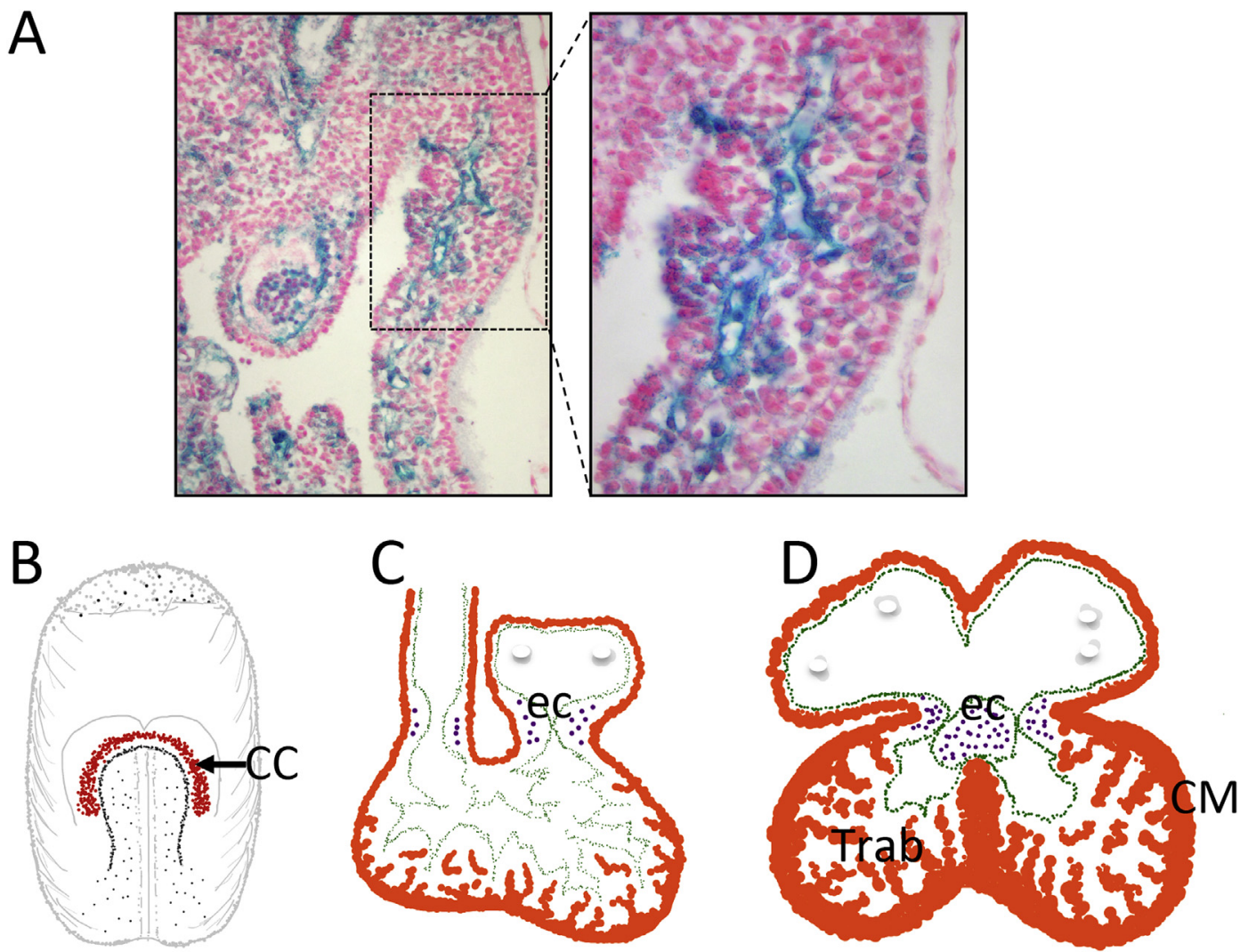

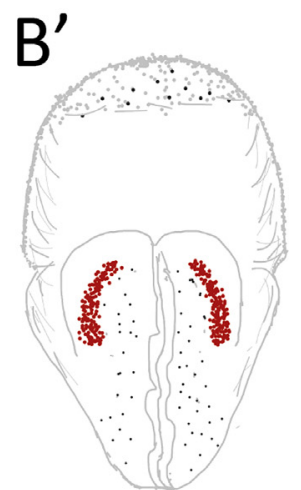

E7.5

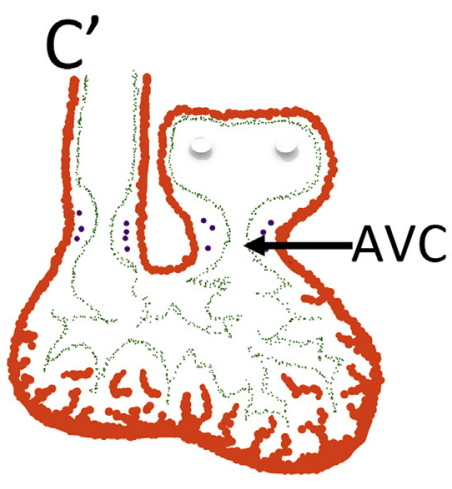

E9.5

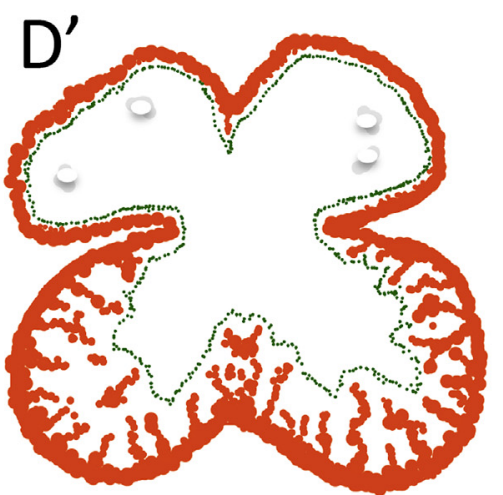

E11.5

Fig. 4. Role of LPP3 in cardiovascular development.

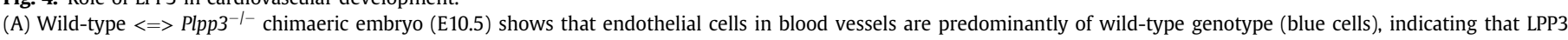

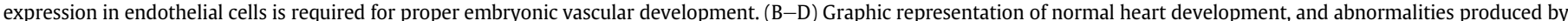

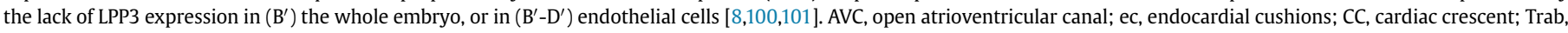

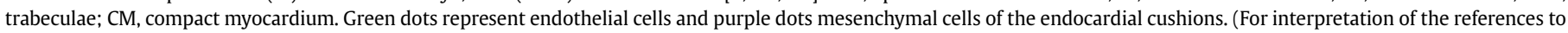
colour in this figure legend, the reader is referred to the Web version of this article.)

arthritis, a disease associated with accelerated atherosclerosis and increased cardiovascular mortality. No association was found between each polymorphism and intima-media thickness, carotid plaques and cardiovascular disease [121].

Prospective studies have also been carried out to evaluate the predictive value of genetic variants, including PLPP3 rs17114036, on acute cardiovascular events. In a study on 1345 CAD subjects, this SNP was found associated to the risk of major advanced cardiovascular events, that included myocardial infarction, unstable angina, stroke and cardiovascular mortality [122]. A similar trend, despite not reaching statistical significance due to limited power, was found for the association of this genetic variant with incidence of myocardial infarction and CAD in a study from the CHARGE consortium [123]. It is interesting to note that mice lacking LPP3 in myocardial cells have a shorter lifespan and die from myocardial dysfunction and heart failure [124]

A few studies have investigated how PLPP3 genetic variants that are associated with increased CAD risk affect LPP3 expression. The risk allele of rs17114046 was found associated with a $30 \%$ increase in PLPP3 expression in carotid plaques [4]. In a subsequent study, the risk allele of rs6588635, proxy to SNP rs17114036, was found associated with a lower expression of PLPP3 in human aortic endothelial cells (HAEC), both at basal conditions and after stimulation with oxidized phospholipids [125]. More recently, the CAD 
associated variant rs72664324 at the PLPP3 locus showed lower transcriptional response to oxidized LDL in macrophages [126]. Further studies on LPP3 expression in the cellular components of the vascular wall and in the atherosclerotic plaque will be needed to reconcile and fully understand these seemingly contradictory evidences.

\section{LPP3 and atherosclerosis development}

PLPP3 is expressed, even if at different levels, by all tissues/organs [9,75], including the vessel wall and the atherosclerotic plaque. Indeed, LPP3 has been detected in EC, intimal macrophages, and in the smooth muscle cells (SMC) of the media [125].

As discussed in detail at paragraph 3 , in vivo gene targeting approaches and in vitro experiments have allowed the identification of LPP3 as an essential factor in the maintenance of the barrier function of the endothelium and in the preservation of EC homeostasis [101,107]. LPP3 in EC is mostly localized at cell-cell contact sites, where it enhances cell-cell interaction, thus reducing vascular permeability and stabilizing blood vessels [107]. Indeed, targeted deletion of Plpp3 in murine endothelial and hematopoietic cells resulted in increased vascular permeability and inflammationinduced vascular leak [101].

Endothelial LPP3 activity is thus essential for vascular development, but it may also have important implications in atherosclerosis, being alterations of endothelial function a primary condition for the development of arterial plaques. In support of this hypothesis, in vitro studies in HAEC have shown that PLPP3 silencing increases the endothelial expression and production of the inflammatory cytokines interleukin- 6 and -8 , the expression of the chemokine monocyte chemoattractant protein 1 (MCP-1) and leukocyte adhesion to human endothelial monolayers [127]. These effects may be consequent to the maintenance of LPA signalling that, through $\mathrm{LPA}_{1}$ and $\mathrm{LPA}_{3}$ dependent mechanisms, is known to exert a pro-inflammatory effect by inducing cytokine/chemokine expression and subsequently promoting monocyte chemotaxis toward EC [128]. Additionally, being a known chemoattractant for lymphocytes, S1P could also be implicated in the observed effects [58]. Altogether, these data strongly support a protective role of LPP3 against endothelial dysfunction and atherosclerosis (Fig. 5). It has also been shown that endothelial LPP3 expression is sensitive to shear stress, being lower in those arterial districts mainly exposed to disturbed blood flow, i.e. in atherosclerosis-susceptible districts [129]. This observation suggests that LPP3 plays a relevant role in maintaining the integrity of the endothelial monolayer mostly in a condition of athero-protective flow and highlights the need for further investigations to fully understand the impact of endothelium-derived LPP3 in atherosclerosis development.

The role of LPP3 expression in SMC was deeply investigated in a murine model of vascular injury, which was induced through dissection and ligation of the common carotid arteries [130]. Arterial injury was shown to enhance LPP3 expression that peaked 14 days after. In order to understand the pathophysiological role of LPP3 in SMC, in vitro overexpression and in vivo targeted-deletion approaches were attempted. LPP3 overexpression in cultured SMC was shown to reduce cell migration and proliferation, at least in part through the attenuation of LPA-mediated signalling [130]. Finally, when the carotid ligation method was applied to mice where Plpp3 expression was conditionally deleted in SMC, increased vascular inflammation and neointimal formation were observed [130]. These results suggest that SMC-derived LPP3 may play a relevant role in the regulation of intimal hyperplasia (Fig. 5).

Altogether, LPP3 of vascular origin seems to be strongly involved in the maintenance of vascular health, since conditions leading to a lower LPP3 expression in the cellular components of the vessel wall

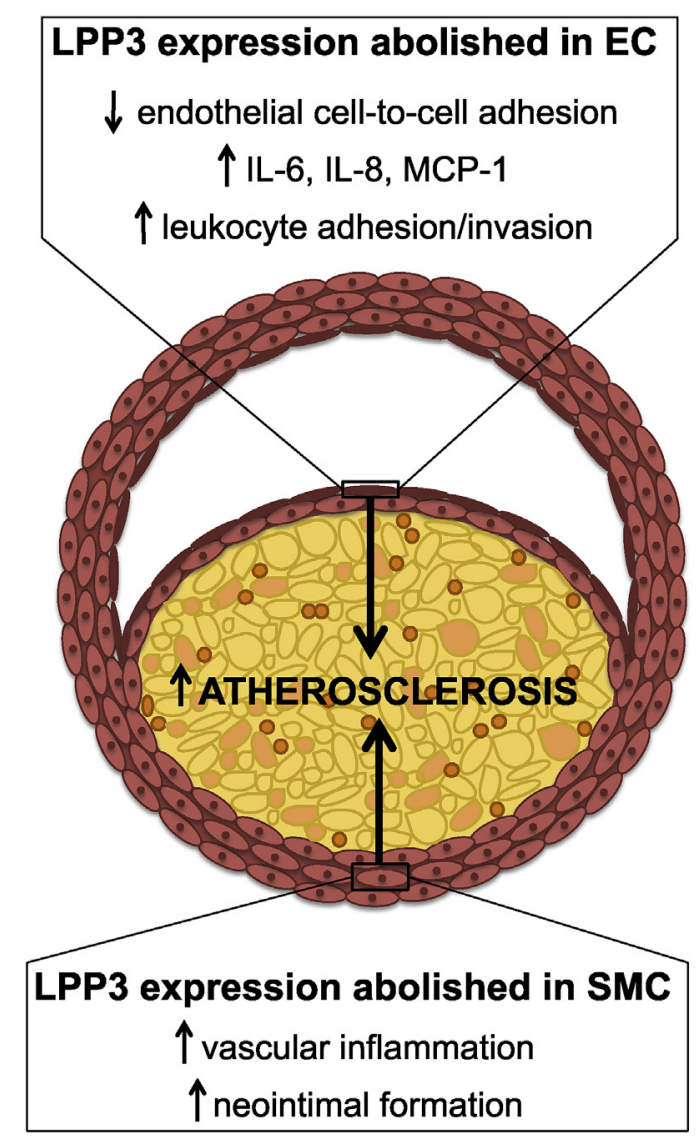

Fig. 5. Consequences of LPP3 deletion in vascular cells.

The abolishment of LPP3 expression in cells that constitute the arterial wall associates with several pro-atherogenic features. When LPP3 expression is abolished in endothelial cells (EC): (i) the barrier function of the endothelium is compromised; (ii) an increased expression of pro-inflammatory cytokines/chemokines IL-6, IL-8 and MCP-1 as well as, (iii) an increased adhesion/invasion of leukocytes are observed. The lack of LPP3 in smooth muscle cells (SMC) promotes vascular inflammation and SMC proliferation, leading to neointimal formation.

result in endothelial dysfunction and SMC proliferation.

A major factor affecting the pathogenesis of atherosclerosis is the exposure of the vessel wall to the lipids circulating within lipoprotein particles, which play a relevant role in the onset of endothelial dysfunction and lesion formation [131]. Lipoproteins carry not only cholesterol, but also hundreds of other lipid species [1], including LPP3 substrates/products [132]. Based on these considerations, being the liver the main source of circulating plasma lipoproteins, it was investigated if a liver-specific Plpp3 deletion could affect atherosclerosis development. Targeted hepatic Plpp3 deletion was then conditionally induced in atherosclerosis-prone ApoE $E^{-1-}$ mice. When fed a Western diet, hepatic $\mathrm{Plpp}^{-1-}$ mice developed larger atherosclerotic plaques compared with Plpp3 expressing mice [9]. This effect was accompanied by several modifications in the plasma lipid composition. Specifically, hepatic $\mathrm{Plpp}^{-1-}$ mice displayed increased plasma concentrations of TG and LPA, whose levels, as described above, have been associated with atherosclerosis worsening in animal models [36], and with the occurrence of acute coronary syndromes in humans [37]. Additionally, elevation of other low-abundant lipids with a known proatherogenic role, such as lysophosphatidylinositols and lactosylceramides were observed. These results indicate that LPP3 may contribute to vascular health, not only directly, through its expression within the cells of the vascular wall, but also indirectly, 


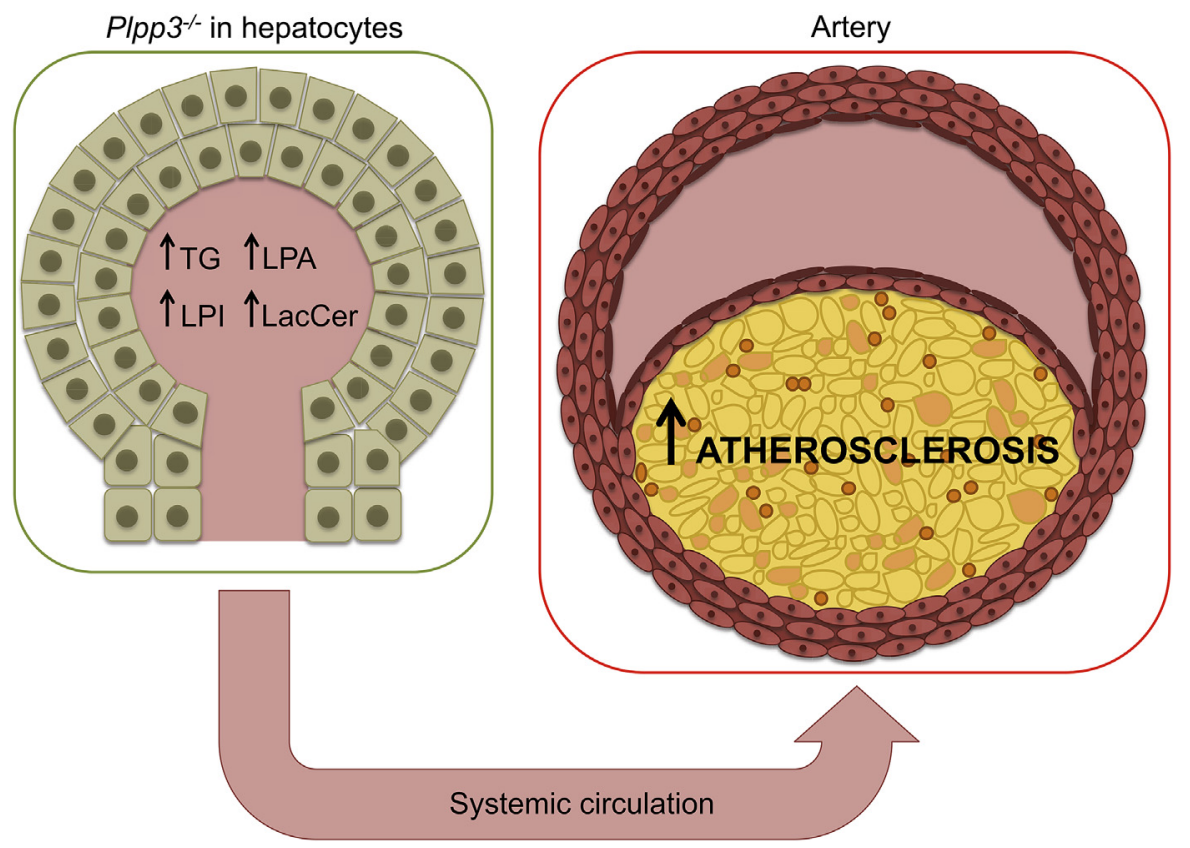

Fig. 6. Hepatic Plpp3 deletion in mice worsens atherosclerosis development.

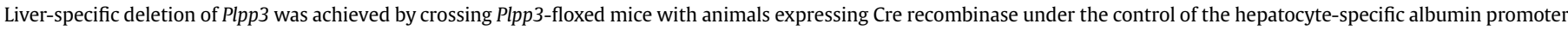

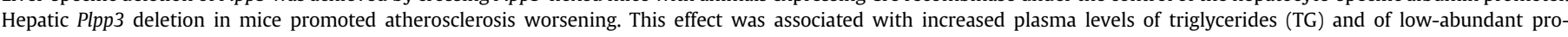
atherogenic lipids, namely lysophosphatidic acid (LPA), lysophosphatidylinositol (LPI) and lactosylceramide (LacCer).

through the modification of the plasma lipidome (Fig. 6). Moreover, since LPP3 dephosphorylates numerous lipid substrates, its effects may involve not only the most investigated and well known targets, LPA and S1P, but also other several biologically-active low-abundant lipids, whose functions are not completely understood. Finally, the aforementioned work constituted the first direct demonstration of the role of Plpp3/LPP3 in atherosclerosis development and provided evidence supporting clinical observations relating PLPP3 polymorphisms to CAD susceptibility.

\section{Conclusions}

LPP3 regulates intracellular and extracellular LPA and S1P signalling through the dephosphorylation of these bioactive lipids. However, having a large number of substrates, LPP3 may play a role in several other less explored pathways.

Experimental studies have indicated that LPP3 activity is crucial for vascular and heart development. LPP3 deficiency, specifically targeted at vascular cell types, induces endothelial permeability, promotes leukocyte adhesion to EC, and stimulates SMC proliferation. Interestingly, hepatocyte-specific Plpp3 deficiency, by modulating the plasma lipidome, exacerbates atherosclerosis development in $A_{p o e^{-1-}}$ mice. These observations are in agreement with GWAS results, showing an association between PLPP3 SNP and increased CAD risk, and indicate metabolic pathways involving LPP3 as relevant targets for the treatment of cardiovascular disease.

\section{Conflict of interest}

The authors declare they do not have anything to disclose regarding conflict of interest with respect to this manuscript.

\section{Financial support}

This work was funded by the European Community's Seventh Framework Programme (FP7/2007-2013) AtheroRemo, grant no.
201668, the European Community's Seventh Framework Programme (FP7/2012-2017) RiskyCAD, grant no. 305739 and by Fondazione Cariplo (2011-0645).

\section{Acknowledgements}

We are grateful to Dr. Mario Luca Morieri for the helpful discussion. We are in debt to Ms. Elda Desiderio Pinto for administrative assistance.

\section{References}

[1] K. Ekroos, M. Janis, K. Tarasov, R. Hurme, R. Laaksonen, Lipidomics: a tool for studies of atherosclerosis, Curr. Atherosclerosis Rep. 12 (2010) 273-281, https://doi.org/10.1007/s11883-010-0110-y.

[2] J.M. Cheng, M. Suoniemi, I. Kardys, T. Vihervaara, S.P. de Boer, et al., Plasma concentrations of molecular lipid species in relation to coronary plaque characteristics and cardiovascular outcome: results of the ATHEROREMOIVUS study, Atherosclerosis 24 (2015) 560-566, https://doi.org/10.1016/ j.atherosclerosis.2015.10.022.

[3] H. Schunkert, I.R. Konig, S. Kathiresan, M.P. Reilly, T.L. Assimes, et al., Largescale association analysis identifies 13 new susceptibility loci for coronary artery disease, Nat. Genet. 43 (2011) 333-338, https://doi.org/10.1038/ ng.784.

[4] Coronary Artery Disease (C4D) Genetics Consortium, A genome-wide association study in Europeans and South Asians identifies five new loci for coronary artery disease, Nat. Genet. 43 (2011) 339-344, https://doi.org/ 10.1038/ng.782.

[5] CARDIoGRAMplusC4D Consortium, P. Deloukas, S. Kanoni, C. Willenborg M. Farrall, T.L. Assimes, et al., Large-scale association analysis identifies new risk loci for coronary artery disease, Nat. Genet. 45 (2013) 25-33, https:// doi.org/10.1038/ng.2480.

[6] M. Nikpay, A. Goel, H.H. Won, L.M. Hall, C. Willenborg, et al, A comprehensive 1,000 Genomes-based genome-wide association metaanalysis of coronary artery disease, Nat. Genet. 47 (2015) 1121-1130, https://doi.org/10.1038/ng.3396.

[7] V.A. Sciorra, A.J. Morris, Roles for lipid phosphate phosphatases in regulation of cellular signaling, Biochim. Biophys. Acta 1582 (2002) 45-51.

[8] I. Chatterjee, J. Baruah, E.E. Lurie, K.K. Wary, Endothelial lipid phosphate phosphatase-3 deficiency that disrupts the endothelial barrier function is a modifier of cardiovascular development, Cardiovasc. Res. 111 (2016) 105-118, https://doi.org/10.1093/cvr/cvw090.

[9] M. Busnelli, S. Manzini, M. Hilvo, C. Parolini, G.S. Ganzetti, et al., Liver-specific 
deletion of the Plpp3 gene alters plasma lipid composition and worsens atherosclerosis in apoE-/- mice, Sci. Rep. 7 (2017) 44503, https://doi.org $10.1038 /$ srep44503.

[10] Z. Jamal, A. Martin, A. Gomez-Munoz, D.N. Brindley, Plasma membrane fractions from rat liver contain a phosphatidate phosphohydrolase distinct from that in the endoplasmic reticulum and cytosol, J. Biol. Chem. 266 (1991) 2988-2996.

[11] D.W. Waggoner, A. Gomez-Munoz, J. Dewald, D.N. Brindley, Phosphatidate phosphohydrolase catalyzes the hydrolysis of ceramide 1-phosphate, lysophosphatidate, and sphingosine 1-phosphate, J. Biol. Chem. 271 (1996) 16506-16509.

[12] D.A. Dillon, X. Chen, G.M. Zeimetz, W.I. Wu, D.W. Waggoner, et al., Mammalian Mg2+-independent phosphatidate phosphatase (PAP2) displays diacylglycerol pyrophosphate phosphatase activity, J. Biol. Chem. 272 (1997) $10361-10366$

[13] S.B. Hooks, S.P. Ragan, K.R. Lynch, Identification of a novel human phosphatidic acid phosphatase type 2 isoform, FEBS Lett. 427 (1998) 188-192.

[14] J.S. Long, N.J. Pyne, S. Pyne, Lipid phosphate phosphatases form homo- and hetero-oligomers: catalytic competency, subcellular distribution and function, Biochem. J. 411 (2008) 371-377, https://doi.org/10.1042/BJ20071607.

[15] V.A. Sciorra, A.J. Morris, Sequential actions of phospholipase D and phosphatidic acid phosphohydrolase $2 \mathrm{~b}$ generate diglyceride in mammalian cells, Mol. Biol. Cell 10 (1999) 3863-3876.

[16] M. Nanjundan, F. Possmayer, Pulmonary lipid phosphate phosphohydrolase in plasma membrane signalling platforms, Biochem. J. 358 (2001) 637-646.

[17] D.N. Brindley, C. Pilquil, Lipid phosphate phosphatases and signaling, J. Lipid Res. 50 (Suppl) (2009) S225-S230, https://doi.org/10.1194/jlr.R800055JLR200.

[18] X. Tang, M.G. Benesch, D.N. Brindley, Lipid phosphate phosphatases and their roles in mammalian physiology and pathology, J. Lipid Res. 56 (2015) 2048-2060, https://doi.org/10.1194/jlr.R058362.

[19] Y.J. Sigal, M.I. McDermott, A.J. Morris, Integral membrane lipid phosphatases/ phosphotransferases: common structure and diverse functions, Biochem. 387 (2005) 281-293.

[20] A. Messerschmidt, R. Wever, X-ray structure of a vanadium-containing enzyme: chloroperoxidase from the fungus Curvularia inaequalis, Proc. Natl. Acad. Sci. U. S. A. 93 (1996) 392-396

[21] A. Messerschmidt, L. Prade, R. Wever, Implications for the catalytic mechanism of the vanadium-containing enzyme chloroperoxidase from the fungus Curvularia inaequalis by $\mathrm{X}$-ray structures of the native and peroxide form, Biol. Chem. 378 (1997) 309-315.

[22] W.H. Moolenaar, L.A. van Meeteren, B.N. Giepmans, The ins and outs of lysophosphatidic acid signaling, Bioessays 26 (2004) 870-881.

[23] D.N. Brindley, Hepatic secretion of lysphosphatidylcholine: a novel transport system for polyunsaturated fatty acids and choline, J. Nutr. Biochem. 4 (1993) 442-449.

[24] D.N. Brindley, Lipid phosphate phosphatases and related proteins: signaling functions in development, cell division, and cancer, J. Cell. Biochem. 92 (2004) 900-912.

[25] O. Fourcade, M.F. Simon, C. Viode, N. Rugani, F. Leballe, et al., Secretory phospholipase A2 generates the novel lipid mediator lysophosphatidic acid in membrane microvesicles shed from activated cells, Cell 80 (1995) 919-927.

[26] T. Sano, D. Baker, T. Virag, A. Wada, Y. Yatomi, T. Kobayashi, Y. Igarashi, G. Tigyi, Multiple mechanisms linked to platelet activation result in lysophosphatidic acid and sphingosine 1-phosphate generation in blood, J. Biol. Chem. 277 (2002) 21197-21206.

[27] S. Llona-Minguez, A. Ghassemian, T. Helleday, Lysophosphatidic acid receptor (LPAR) modulators: the current pharmacological toolbox, Prog. Lipid Res. 58 (2015) 51-75, https://doi.org/10.1016/j.plipres.2015.01.004.

[28] G.B. Mills, W.H. Moolenaar, The emerging role of lysophosphatidic acid in cancer, Nat. Rev. Canc. 3 (2003) 582-591.

[29] E. Birgbauer, J. Chun, New developments in the biological functions of lysophospholipids, Cell. Mol. Life Sci. 63 (2006) 2695-2701, https://doi.org/ 10.1007/s00018-006-6155-y.

[30] U. Ray, S.S. Roy, Aberrant lipid metabolism in cancer cells - the role of oncolipid-activated signaling, FEBS J. (2017), https://doi.org/10.1111/ febs.14281 [Epub ahead of print].

[31] R. Ray, V. Rai, Lysophosphatidic acid converts monocytes into macrophages in both mice and humans, Blood 129 (2017) 1177-1183, https://doi.org/ 10.1182/blood-2016-10-743757.

[32] Z. Bai, L. Cai, E. Umemoto, A. Takeda, K. Tohya, et al., Constitutive lymphocyte transmigration across the basal lamina of high endothelial venules is regulated by the autotaxin/lysophosphatidic acid axis, J. Immunol. 190 (2013) 2036-2048, https://doi.org/10.4049/jimmunol.1202025.

[33] Y. Zhang, Y.C. Chen, M.F. Krummel, S.D. Rosen, Autotaxin through lysophosphatidic acid stimulates polarization, motility, and transendothelial migration of naive T cells, J. Immunol. 189 (2012) 3914-3924, https:/ doi.org/10.4049/jimmunol.1201604.

[34] T. Nakasaki, T. Tanaka, S. Okudaira, M. Hirosawa, E. Umemoto, et al., Involvement of the lysophosphatidic acid-generating enzyme autotaxin in lymphocyte-endothelial cell interactions, Am. J. Pathol. 173 (2008) 1566-1576, https://doi.org/10.2353/ajpath.2008.071153.

[35] L.A. van Meeteren, W.H. Moolenaar, Regulation and biological activities of the autotaxin-LPA axis, Prog. Lipid Res. 46 (2007) 145-160, https://doi.org/ 10.1016/j.plipres.2007.02.001

[36] M. Bot, S.C. de Jager, L. MacAleese, H.M. Lagraauw, TJ. van Berkel, et al. Lysophosphatidic acid triggers mast cell-driven atherosclerotic plaque destabilization by increasing vascular inflammation, J. Lipid Res. 54 (2013) 1265-1274, https://doi.org/10.1194/jlr.M032862.

[37] M. Kurano, A. Suzuki, A. Inoue, Y. Tokuhara, K. Kano, et al., Possible involvement of minor lysophospholipids in the increase in plasma lysophosphatidic acid in acute coronary syndrome, Arterioscler. Thromb. Vasc. Biol. 35 (2015) 463-470, https://doi.org/10.1161/ATVBAHA.114.304748.

[38] W. Siess, G. Tigyi, Thrombogenic and atherogenic activities of lysophosphatidic acid, J. Cell. Biochem. 92 (2004) 1086-1094, https://doi.org/ 10.1002/jcb.20108.

[39] A.K. Salous, M. Panchatcharam, M. Sunkara, P. Mueller, A. Dong, et al., Mechanism of rapid elimination of lysophosphatidic acid and related lipids from the circulation of mice, J. Lipid Res. 54 (2013) 2775-2784, https:// doi.org/10.1194/jlr.M039685.

[40] R.L. Proia, T. Hla, Emerging biology of sphingosine-1-phosphate: its role in pathogenesis and therapy, J. Clin. Invest. 125 (2015) 1379-1387, https:// doi.org/10.1172/JCI76369.

[41] A.H. Merrill Jr., Sphingolipid and glycosphingolipid metabolic pathways in the era of sphingolipidomics, Chem. Rev. 111 (2011) 6387-6422, https:// doi.org/10.1021/cr2002917.

[42] K. Venkataraman, Y.M. Lee, J. Michaud, S. Thangada, Y. Ai, et al., Vascular endothelium as a contributor of plasma sphingosine 1-phosphate, Circ. Res. 102 (2008) 669-676, https://doi.org/10.1161/CIRCRESAHA.107.165845.

[43] Y. Hisano, N. Kobayashi, A. Yamaguchi, T. Nishi, Mouse SPNS2 functions as a sphingosine-1-phosphate transporter in vascular endothelial cells, PLoS One 7 (2012), e38941, https://doi.org/10.1371/journal.pone.0038941.

[44] R. Pappu, S.R. Schwab, I. Cornelissen, J.P. Pereira, J.B. Regard, et al., Promotion of lymphocyte egress into blood and lymph by distinct sources of sphingosine-1-phosphate, Science 316 (2007) 295-298, https://doi.org/10.1126/ science.1139221.

[45] S. Fukuhara, S. Simmons, S. Kawamura, A. Inoue, Y. Orba, et al., The sphingosine-1-phosphate transporter Spns2 expressed on endothelial cells regulates lymphocyte trafficking in mice, J. Clin. Invest. 122 (2012) 1416-1426, https://doi.org/10.1172/JCI60746.

[46] K.M. Argraves, W.S. Argraves, HDL serves as a S1P signaling platform mediating a multitude of cardiovascular effects, J. Lipid Res. 48 (2007) 2325-2333, https://doi.org/10.1194/jlr.R700011-JLR200.

[47] K. Mendelson, T. Zygmunt, J. Torres-Vazquez, T. Evans, T. Hla, Sphingosine 1phosphate receptor signaling regulates proper embryonic vascular patterning, J. Biol. Chem. 288 (2013) 2143-2156, https://doi.org/10.1074/ jbc.M112.427344.

[48] E. Camerer, J.B. Regard, I. Cornelissen, Y. Srinivasan, D.N. Duong, et al., Sphingosine-1-phosphate in the plasma compartment regulates basal and inflammation-induced vascular leak in mice, J. Clin. Invest. 119 (2009) 1871-1879.

[49] J.N. Lorenz, L.J. Arend, R. Robitz, R.J. Paul, A.J. MacLennan, Vascular dysfunction in S1P2 sphingosine 1-phosphate receptor knockout mice, Am. J. Physiol. Regul. Integr. Comp. Physiol. 292 (2007) R440-R446, https://doi.org/ 10.1152/ajpregu.00085.2006.

[50] J.G. Cyster, S.R. Schwab, Sphingosine-1-phosphate and lymphocyte egress from lymphoid organs, Annu. Rev. Immunol. 30 (2012) 69-94, https:// doi.org/10.1146/annurev-immunol-020711-075011.

[51] J.G. Juarez, N. Harun, M. Thien, R. Welschinger, R. Baraz, et al., Sphingosine-1phosphate facilitates trafficking of hematopoietic stem cells and their mobilization by CXCR4 antagonists in mice, Blood 119 (2012) 707-716, https://doi.org/10.1182/blood-2011-04-348904.

[52] K. Mizugishi, T. Yamashita, A. Olivera, G.F. Miller, S. Spiegel, et al., Essential role for sphingosine kinases in neural and vascular development, Mol. Cell Biol. 25 (2005) 11113-11121, https://doi.org/10.1128/MCB.25.24.1111311121.2005.

[53] N.J. Pyne, S. Pyne, Sphingosine 1-phosphate and cancer, Nat. Rev. Canc. 10 (2010) 489-503, https://doi.org/10.1038/nrc2875.

[54] M.L. Ng, C. Wadham, O.A. Sukocheva, The role of sphingolipid signalling in diabetesassociated pathologies (Review), Int. J. Mol. Med. 39 (2017) 243-252, https://doi.org/10.3892/ijmm.2017.2855.

[55] A. Kawahara, T. Nishi, Y. Hisano, H. Fukui, A. Yamaguchi, et al., The sphingolipid transporter spns2 functions in migration of zebrafish myocardial precursors, Science 323 (2009) 524-527, https://doi.org/10.1126/ science. 1167449.

[56] A. Koch, J. Pfeilschifter, A. Huwiler, Sphingosine 1-phosphate in renal diseases, Cell. Physiol. Biochem. 31 (2013) 745-760, https://doi.org/10.1159/ 000350093.

[57] Y. Mao-Draayer, J. Sarazin, D. Fox, E. Schiopu, The sphingosine-1-phosphate receptor: a novel therapeutic target for multiple sclerosis and other autoimmune diseases, Clin. Immunol. 175 (2017) 10-15, https://doi.org/10.1016/ j.clim.2016.11.008.

[58] M. Kurano, Y. Yatomi, Sphingosine 1-phosphate and atherosclerosis, J. Atherosclerosis Thromb. (2017), https://doi.org/10.5551/jat.RV17010 [Epub ahead of print].

[59] F. Poti, M. Simoni, J.R. Nofer, Atheroprotective role of high-density lipoprotein (HDL)-associated sphingosine-1-phosphate (S1P), Cardiovasc. Res. 103 (2014) 395-404, https://doi.org/10.1093/cvr/cvu136.

[60] T. Kimura, K. Sato, A. Kuwabara, H. Tomura, M. Ishiwara, et al., Sphingosine 
1-phosphate may be a major component of plasma lipoproteins responsible for the cytoprotective actions in human umbilical vein endothelial cells, J. Biol. Chem. 276 (2001) 31780-31785, https://doi.org/10.1074/ jbc.M104353200.

[61] J.R. Nofer, B. Levkau, I. Wolinska, R. Junker, M. Fobker, et al., Suppression of endothelial cell apoptosis by high density lipoproteins (HDL) and HDLassociated lysosphingolipids, J. Biol. Chem. 276 (2001) 34480-34485, https://doi.org/10.1074/jbc.M104353200.

[62] T. Kimura, K. Sato, E. Malchinkhuu, H. Tomura, K. Tamama, et al., Highdensity lipoprotein stimulates endothelial cell migration and survival through sphingosine 1-phosphate and its receptors, Arterioscler. Thromb. Vasc. Biol. 23 (2003) 1283-1288, https://doi.org/10.1161/ 01.ATV.0000079011.67194.5A.

[63] K.M. Argraves, P.J. Gazzolo, E.M. Groh, B.A. Wilkerson, B.S. Matsuura, et al., High density lipoprotein-associated sphingosine 1-phosphate promotes endothelial barrier function, J. Biol. Chem. 283 (2008) 25074-25081, https:// doi.org/10.1074/jbc.M801214200.

[64] J.R. Nofer, M. van der Giet, M. Tolle, I. Wolinska, K. von Wnuck, et al., HDL induces NO-dependent vasorelaxation via the lysophospholipid receptor S1P3, J. Clin. Invest. 113 (2004) 569-581, https://doi.org/10.1172/JCI18004.

[65] T. Kimura, H. Tomura, C. Mogi, A. Kuwabara, A. Damirin, et al., Role of scavenger receptor class B type I and sphingosine 1-phosphate receptors in high density lipoprotein-induced inhibition of adhesion molecule expression in endothelial cells, J. Biol. Chem. 281 (2006) 37457-37467, https://doi.org/ 10.1074/jbc.M605823200

[66] M. Ruiz, C. Frej, A. Holmer, L.J. Guo, S. Tran, et al., High-density lipoproteinassociated apolipoprotein $\mathrm{m}$ limits endothelial inflammation by delivering sphingosine-1-phosphate to the sphingosine-1-phosphate receptor 1, Arterioscler. Thromb. Vasc. Biol. 37 (2017) 118-129, https://doi.org/10.1161/ ATVBAHA.116.308435.

[67] E.J. Goetzl, M.H. Graler, Sphingosine 1-phosphate and its type 1 G proteincoupled receptor: trophic support and functional regulation of $\mathrm{T}$ lymphocytes, J. Leukoc. Biol. 76 (2004) 30-35, https://doi.org/10.1189/jlb.1103567.

[68] D.J. Swan, J.A. Kirby, S. Ali, Vascular biology: the role of sphingosine 1phosphate in both the resting state and inflammation, J. Cell Mol. Med. 14 (2010) 2211-2222, https://doi.org/10.1111/j.1582-4934.2010.01136.x.

[69] P. Keul, S. Lucke, K. von Wnuck Lipinski, C. Bode, M. Graler, et al., Sphingosine-1-phosphate receptor 3 promotes recruitment of monocyte/macrophages in inflammation and atherosclerosis, Circ. Res. 108 (2011) 314-323, https://doi.org/10.1161/CIRCRESAHA.110.235028.

[70] N.D. Lewis, S.A. Haxhinasto, S.M. Anderson, D.E. Stefanopoulos, S.E. Fogal, et al., Circulating monocytes are reduced by sphingosine-1-phosphate receptor modulators independently of S1P3, J. Immunol. 190 (2013) 3533-3540, https://doi.org/10.4049/jimmunol.1201810.

[71] M. Ksiazek, M. Chacinska, A. Chabowski, M. Baranowski, Sources, metabolism, and regulation of circulating sphingosine-1-phosphate, J. Lipid Res. 56 (2015) 1271-1281, https://doi.org/10.1194/jlr.R059543.

[72] B. Breart, W.D. Ramos-Perez, A. Mendoza, A.K. Salous, M. Gobert, Y. Huang R.H. Adams, J.J. Lafaille, D. Escalante-Alcalde, A.J. Morris, S.R. Schwab, Lipid phosphate phosphatase 3 enables efficient thymic egress, J. Exp. Med. 208 (2011) 1267-1278, https://doi.org/10.1084/jem.20102551.

[73] A. Lopez-Juarez, S. Morales-Lazaro, R. Sanchez-Sanchez, M. Sunkara, H. Lomeli, et al., Expression of LPP3 in Bergmann glia is required for proper cerebellar sphingosine-1-phosphate metabolism/signaling and development, Glia 59 (2011) 577-589, https://doi.org/10.1002/glia.21126.

[74] W.D. Ramos-Perez, V. Fang, D. Escalante-Alcalde, M. Cammer, S.R. Schwab, A map of the distribution of sphingosine 1-phosphate in the spleen, Nat. Immunol. 16 (2015) 1245-1252, https://doi.org/10.1038/ni.3296.

[75] M. Kai, I. Wada, S. Imai, F. Sakane, H. Kanoh, Cloning and characterization of two human isozymes of Mg2+-independent phosphatidic acid phosphatase, J. Biol. Chem. 272 (1997) 24572-24578.

[76] D. Barila, M. Plateroti, F. Nobili, A.O. Muda, Y. Xie, et al., The Dri 42 gene, whose expression is up-regulated during epithelial differentiation, encodes a novel endoplasmic reticulum resident transmembrane protein, J. Biol. Chem. 271 (1996) 29928-29936.

[77] B.J. Pettus, K. Kitatani, C.E. Chalfant, T.A. Taha, T. Kawamori, et al., The coordination of prostaglandin E2 production by sphingosine-1-phosphate and ceramide-1-phosphate, Mol. Pharmacol. 68 (2005) 330-335, https://doi.org/ 10.1124/mol.104.008722.

[78] N.C. Hait, J. Allegood, M. Maceyka, G.M. Strub, K.B. Harikumar, et al., Regulation of histone acetylation in the nucleus by sphingosine-1-phosphate, Science 325 (5945) (2009) 1254-1257, https://doi.org/10.1126/ science.1176709.

[79] M. Maceyka, S.G. Payne, S. Milstien, S. Spiegel, Sphingosine kinase, sphingosine-1-phosphate, and apoptosis, Biochim. Biophys. Acta 1585 (2002) $193-201$.

[80] M.A. Rizzo, K. Shome, C. Vasudevan, D.B. Stolz, T.C. Sung, M.A. Frohman, S.C. Watkins, G. Romero, Phospholipase D and its product, phosphatidic acid, mediate agonist-dependent raf- 1 translocation to the plasma membrane and the activation of the mitogen-activated protein kinase pathway, J. Biol. Chem. 274 (1999) 1131-1139.

[81] B.T. Andresen, M.A. Rizzo, K. Shome, G. Romero, The role of phosphatidic acid in the regulation of the Ras/MEK/Erk signaling cascade, FEBS Lett. 531 (2002) 65-68.

[82] E. Gutierrez-Martinez, I. Fernandez-Ulibarri, F. Lazaro-Dieguez, L. Johannes,
S. Pyne, et al., Lipid phosphate phosphatase 3 participates in transport Carrier formation and protein trafficking in the early secretory pathway, J. Cell Sci. 126 (2013) 2641-2655, https://doi.org/10.1242/jcs.117705.

[83] J. Long, P. Darroch, K.F. Wan, K.C. Kong, N. Ktistakis, et al., Regulation of cell survival by lipid phosphate phosphatases involves the modulation of intracellular phosphatidic acid and sphingosine 1-phosphate pools, Biochem. J. 391 (2005) 25-32, https://doi.org/10.1042/BJ20050342.

[84] J.O. Humtsoe, S. Feng, G.D. Thakker, J. Yang, J. Hong, et al., Regulation of cellcell interactions by phosphatidic acid phosphatase 2b/VCIP, EMBO J. 22 (2003) 1539-1554, https://doi.org/10.1093/emboj/cdg165.

[85] J.O. Humtsoe, R.A. Bowling Jr., S. Feng, K.K. Wary, Murine lipid phosphate phosphohydrolase- 3 acts as a cell-associated integrin ligand, Biochem. Biophys. Res. Commun. 335 (2005) 906-919, https://doi.org/10.1016/ j.bbrc.2005.07.157.

[86] H. Ren, M. Panchatcharam, P. Mueller, D. Escalante-Alcalde, A.J. Morris, et al. Lipid phosphate phosphatase (LPP3) and vascular development, Biochem. Biophys. Acta 1831 (2013) 126-132, https://doi.org/10.1016 j.bbalip.2012.07.012.

[87] NCBI Resource Coordinators, Database resources of the national center for biotechnology information, Nucleic Acids Res. 44 (2016) D7-D19, https:// doi.org/10.1093/nar/gkv1290.

[88] N.G. Seidah, Z. Awan, M. Chretien, M. Mbikay, PCSK9: a key modulator of cardiovascular health, Circ. Res. 114 (2014) 1022-1036, https://doi.org/ 10.1161/CIRCRESAHA.114.301621.

[89] M. Fuchs, A. Hafer, C. Munch, F. Kannenberg, S. Teichmann, et al., Disruption of the sterol Carrier protein 2 gene in mice impairs biliary lipid and hepatic cholesterol metabolism, J. Biol. Chem. 276 (2001) 48058-48065, https:/ doi.org/10.1074/jbc.M106732200.

[90] M. Ngo, N.D. Ridgway, Oxysterol binding protein-related Protein 9 (ORP9) is a cholesterol transfer protein that regulates Golgi structure and function, Mol. Biol. Cell 20 (2009) 1388-1399, https://doi.org/10.1091/mbc.E08-090905.

[91] E.J. Zerenturk, L.J. Sharpe, E. Ikonen, A.J. Brown, Desmosterol and DHCR24: unexpected new directions for a terminal step in cholesterol synthesis, Prog. Lipid Res. 52 (2013) 666-680, https://doi.org/10.1016/j.plipres.2013.09.002.

[92] G.Q. Shen, D. Girelli, L. Li, S. Rao, S. Archacki, et al., A novel molecular diagnostic marker for familial and early-onset coronary artery disease and myocardial infarction in the LRP8 gene, Circ. Cardiovasc. Genet. 7 (2014) 514-520, https://doi.org/10.1161/CIRCGENETICS.113.000321.

[93] Y. Zhang, Y. Li, M.W. Niepel, Y. Kawano, S. Han, et al., Targeted deletion of thioesterase superfamily member 1 promotes energy expenditure and protects against obesity and insulin resistance, Proc. Natl. Acad. Sci. U. S. A. 109 (2012) 5417-5422, https://doi.org/10.1073/pnas.1116011109.

[94] J. Lee, J. Choi, S. Aja, S. Scafidi, M.J. Wolfgang, Loss of adipose fatty acid oxidation does not potentiate obesity at thermoneutrality, Cell Rep. 14 (2016) 1308-1316, https://doi.org/10.1016/j.celrep.2016.01.029.

[95] J. Du, Z. Li, Q.Z. Li, T. Guan, Q. Yang, et al., Enoyl coenzyme a hydratase domain-containing 2, a potential novel regulator of myocardial ischemia injury, J. Am. Heart. Assoc. 2 (2013), https://doi.org/10.1161/ JAHA.113.000233 e000233.

[96] D. Israel, S. Chua Jr., Leptin receptor modulation of adiposity and fertility, Trends Endocrinol. Metabol. 21 (2010) 10-16, https://doi.org/10.1016/ j.tem.2009.07.004

[97] M. Safran, I. Dalah, J. Alexander, N. Rosen, T. Iny Stein, et al., GeneCards Version 3: the human gene integrator, Database 2010 (2010) baq020, https://doi.org/10.1093/database/baq020.

[98] J.L. Tomsig, A.H. Snyder, E.V. Berdyshev, A. Skobeleva, C. Mataya, et al., Lipid phosphate phosphohydrolase type 1 (LPP1) degrades extracellular lysophosphatidic acid in vivo, Biochem. J. 419 (2009) 611-618, https://doi.org/ 10.1042/BJ20081888.

[99] N. Zhang, J.P. Sundberg, T. Gridley, Mice mutant for Ppap2c, a homolog of the germ cell migration regulator wunen, are viable and fertile, Genesis 27 (2000) 137-140

[100] D. Escalante-Alcalde, L. Hernandez, H. Le Stunff, R. Maeda, H.S. Lee, et al., The lipid phosphatase LPP3 regulates extra-embryonic vasculogenesis and axis patterning, Development 130 (2003) 4623-4637, https://doi.org/10.1242/ dev.00635.

[101] M. Panchatcharam, A.K. Salous, J. Brandon, S. Miriyala, J. Wheeler, P. Patil, M. Sunkara, A.J. Morris, D. Escalante-Alcalde, S.S. Smyth, Mice with targeted inactivation of ppap2b in endothelial and hematopoietic cells display enhanced vascular inflammation and permeability, Arterioscler. Thromb. Vasc. Biol. 34 (2014) 837-845, https://doi.org/10.1161/ ATVBAHA.113.302335.

[102] J.O. Humtsoe, M. Liu, A.B. Malik, K.K. Wary, Lipid phosphate phosphatase 3 stabilization of beta-catenin induces endothelial cell migration and formation of branching point structures, Mol. Cell Biol. 30 (2010) 1593-1606, https://doi.org/10.1128/MCB.00038-09.

[103] H. Yukiura, K. Hama, K. Nakanaga, M. Tanaka, Y. Asaoka, et al., Autotaxin regulates vascular development via multiple lysophosphatidic acid (LPA) receptors in zebrafish, J. Biol. Chem. 286 (2011) 43972-43983, https:// doi.org/10.1074/jbc.M111.301093.

[104] Y. Hisano, A. Inoue, K. Taimatsu, S. Ota, R. Ohga, et al., Comprehensive analysis of sphingosine-1-phosphate receptor mutants during zebrafish embryogenesis, Gene Cell. 20 (2015) 647-658, https://doi.org/10.1111/ gtc.12259. 
[105] L.A. van Meeteren, P. Ruurs, C. Stortelers, P. Bouwman, M.A. van Rooijen, et al., Autotaxin, a secreted lysophospholipase D, is essential for blood vessel formation during development, Mol. Cell Biol. 26 (2006) 5015-5022, https:// doi.org/10.1128/MCB.02419-05.

[106] H. Yukiura, K. Kano, R. Kise, A. Inoue, J. Aoki, Autotaxin overexpression causes embryonic lethality and vascular defects, PLoS One 10 (2015), https:// doi.org/10.1371/journal.pone.0126734 e0126734.

[107] H. Yukiura, K. Kano, R. Kise, A. Inoue, J. Aoki, LPP3 localizes LPA6 signalling to non-contact sites in endothelial cells, J. Cell Sci. 128 (2015) 3871-3877, https://doi.org/10.1242/jcs.172098.

[108] Y. Liu, R. Wada, T. Yamashita, Y. Mi, C.X. Deng, et al., Edg-1, the G proteincoupled receptor for sphingosine-1-phosphate, is essential for vascular maturation, J. Clin. Invest. 106 (2000) 951-961, https://doi.org/10.1172/ JCI10905.

[109] Y. Hisano, A. Inoue, M. Okudaira, K. Taimatsu, H. Matsumoto, et al., Maternal and zygotic sphingosine kinase 2 are indispensable for cardiac development in zebrafish, J. Biol. Chem. 290 (2015) 14841-14851, https://doi.org/ 10.1074/jbc.M114.634717.

[110] D. Ye, F. Lin, S1pr2/Galpha13 signaling controls myocardial migration by regulating endoderm convergence, Development 140 (2013) 789-799, https://doi.org/10.1242/dev.085340.

[111] E. Kupperman, S. An, N. Osborne, S. Waldron, D.Y. Stainier, A sphingosine-1phosphate receptor regulates cell migration during vertebrate heart development, Nature 406 (2000) 192-195, https://doi.org/10.1038/35018092.

[112] H. Fukui, K. Terai, H. Nakajima, A. Chiba, S. Fukuhara, et al., S1P-Yap1 signaling regulates endoderm formation required for cardiac precursor cell migration in zebrafish, Dev. Cell 31 (2014) 128-136, https://doi.org/ 10.1016/j.devcel.2014.08.014.

[113] R.R. Poulsen, C.M. McClaskey, S.A. Rivkees, C.C. Wendler, The Sphingosine-1phospate receptor 1 mediates S1P action during cardiac development, BMC Dev. Biol. 11 (2011) 37, https://doi.org/10.1186/1471-213X-11-37.

[114] R. McPherson, A. Tybjaerg-Hansen, Genetics of coronary artery disease, Circ. Res. 118 (2016) 564-578, https://doi.org/10.1161/CIRCRESAHA.115.306566.

[115] B. Mayer, J. Erdmann, H. Schunkert, Genetics and heritability of coronary artery disease and myocardial infarction, Clin. Res. Cardiol. 96 (2007) 1-7, https://doi.org/10.1007/s00392-006-0447-y.

[116] T. Kessler, B. Vilne, H. Schunkert, The impact of genome-wide association studies on the pathophysiology and therapy of cardiovascular disease, EMBO Mol. Med. 8 (2016) 688-701, https://doi.org/10.15252/emmm.201506174.

[117] J.M.M. Howson, W. Zhao, D.R. Barnes, W.K. Ho, R. Young, et al., Fifteen new risk loci for coronary artery disease highlight arterial-wall-specific mechanisms, Nat. Genet. 49 (2017) 1113-1119, https://doi.org/10.1038/ng.3874.

[118] D. Klarin, Q.M. Zhu, C.A. Emdin, M. Chaffin, S. Horner, et al., Genetic analysis in UK Biobank links insulin resistance and transendothelial migration pathways to coronary artery disease, Nat. Genet. 49 (2017) 1392-1397, https://doi.org/10.1038/ng.3914.

[119] C.P. Nelson, A. Goel, A.S. Butterworth, S. Kanoni, T.R. Webb, et al., Association analyses based on false discovery rate implicate new loci for coronary artery disease, Nat. Genet. 49 (2017) 1385-1391, https://doi.org/10.1038/ng.3913.

[120] Y.X. Sun, C.Y. Gao, Y. Lu, X. Fu, J.G. Jia, et al., Association between PPAP2B gene polymorphisms and coronary heart disease susceptibility in Chinese
Han males and females, Oncotarget 8 (2017) 13166-13173, https://doi.org/ 10.18632/oncotarget.14486.

[121] R. Lopez-Mejias, F. Genre, M. Garcia-Bermudez, B. Ubilla, S. Castaneda, et al., Lack of association between ABO, PPAP2B, ADAMST7, PIK3CG, and EDNRA and carotid intima-media thickness, carotid plaques, and cardiovascular disease in patients with rheumatoid arthritis, Mediat. Inflamm. 2014 (2014) 756279, https://doi.org/10.1155/2014/756279.

[122] M. Wirtwein, O. Melander, M. Sjogren, M. Hoffmann, K. Narkiewicz, et al., Relationship between selected DNA polymorphisms and coronary artery disease complications, Int. J. Cardiol. 228 (2017) 814-820, https://doi.org/ 10.1016/j.ijcard.2016.11.060.

[123] A. Dehghan, J.C. Bis, C.C. White, A.V. Smith, A.C. Morrison, et al., Genomewide association study for incident myocardial infarction and coronary heart disease in prospective cohort studies: the CHARGE Consortium, PLoS One 11 (2016), https://doi.org/10.1371/journal.pone.0144997 e0144997.

[124] M. Chandra, D. Escalante-Alcalde, M.S. Bhuiyan, A.W. Orr, C. Kevil, et al., Cardiac-specific inactivation of LPP3 in mice leads to myocardial dysfunction and heart failure, Redox Biol. 14 (2018) 261-271, https://doi.org/10.1016/ j.redox.2017.09.015.

[125] A. Erbilgin, M. Civelek, C.E. Romanoski, C. Pan, R. Hagopian, et al., Identification of CAD candidate genes in GWAS loci and their expression in vascular cells, J. Lipid Res. 54 (2013) 1894-1905, https://doi.org/10.1194/ jlr.M037085.

[126] M.E. Reschen, K.J. Gaulton, D. Lin, E.J. Soilleux, A.J. Morris, et al., Lipidinduced epigenomic changes in human macrophages identify a coronary artery disease-associated variant that regulates PPAP2B Expression through Altered C/EBP-beta binding, PLoS Genet. 11 (2015), https://doi.org/10.1371/ journal.pgen.1005061 e1005061.

[127] Z. Touat-Hamici, H. Weidmann, Y. Blum, C. Proust, H. Durand, et al., Role of lipid phosphate phosphatase 3 in human aortic endothelial cell function, Cardiovasc. Res. 112 (2016) 702-713, https://doi.org/10.1093/cvr/cvw217.

[128] C.I. Lin, C.N. Chen, P.W. Lin, K.J. Chang, F.J. Hsieh, et al., Lysophosphatidic acid regulates inflammation-related genes in human endothelial cells through LPA1 and LPA3, Biochem. Biophys. Res. Commun. 363 (2007) 1001-1008, https://doi.org/10.1016/j.bbrc.2007.09.081.

[129] C. Wu, R.T. Huang, C.H. Kuo, S. Kumar, C.W. Kim, et al., Mechanosensitive PPAP2B regulates endothelial responses to atherorelevant hemodynamic forces, Circ. Res. 117 (2015) e41-e53, https://doi.org/10.1161/ CIRCRESAHA.117.306457.

[130] M. Panchatcharam, S. Miriyala, A. Salous, J. Wheeler, A. Dong, et al., Lipid phosphate phosphatase 3 negatively regulates smooth muscle cell phenotypic modulation to limit intimal hyperplasia, Arterioscler. Thromb. Vasc. Biol. 33 (2013) 52-59, https://doi.org/10.1161/ATVBAHA.112.300527.

[131] P. Libby, P.M. Ridker, G.K. Hansson, Progress and challenges in translating the biology of atherosclerosis, Nature 473 (2011) 317-325, https://doi.org/ 10.1038/nature 10146 .

[132] A. Reis, A. Rudnitskaya, P. Chariyavilaskul, N. Dhaun, V. Melville, et al., Topdown lipidomics of low density lipoprotein reveal altered lipid profiles in advanced chronic kidney disease, J. Lipid Res. 56 (2015) 413-422, https:// doi.org/10.1194/jlr.M055624. 